\title{
Efeito da temperatura e do fotoperíodo na esporulação in vitro de Botrytis squamosa, agente causal da queima das pontas das folhas da cebola
}

\author{
Leandro Luiz Marcuzzo ${ }^{1}$, Sheila Chaiana Harbs ${ }^{1}$
}

${ }^{1}$ Instituto Federal Catarinense - IFC/Campus Rio do Sul, CP 441, 89.163-356, Rio do Sul, SC, Brasil

Autor para correspondência: Leandro Luiz Marcuzzo (leandro.marcuzzo@ifc.edu.br)

Data de chegada: 22/11/2017. Aceito para publicação em: 12/04/2018.

$10.1590 / 0100-5405 / 188176$

A queima das pontas das folhas da cebola causada por Botrytis squamosa (Walker) é considerada a mais importante doença durante a fase de muda da cultura. A doença é comumente encontrada nas condições de ambiente do sul do Brasil, onde são frequentes os períodos de baixa luminosidade ( $\leq 12$ horas), temperaturas amenas $\left(\leq 22^{\circ} \mathrm{C}\right)$ e alta umidade do ar ( $\geq 90 \%$ ) (3). Os sintomas ocorrem nas folhas como manchas esbranquiçadas de forma isolada e não esporulantes, no entanto o sintoma característico de maior dano na planta é a queima da folha, ocorrendo do ápice para a base da folha (2). O patógeno se reproduz sobre as folhas mortas da cultura e serve de inóculo para sua disseminação da doença, no entanto, trabalhos sobre a esporulação do patógeno exigem o conhecimento prévio das condições ambientais necessárias para a produção do inóculo, já que pesquisas relacionadas essa doença no Brasil ainda são escassas. Para tanto, o conhecimento da biologia do patógeno é de grande importância para compreender o desenvolvimento da doença no campo e o seu manejo. Diante disso, este trabalho teve como objetivo avaliar em condições in vitro, o efeito da temperatura e do fotoperíodo na esporulação de conídios de B. squamosa, simulando o que estaria ocorrendo no tecido foliar em condição de campo. O trabalho foi realizado no Laboratório de Microbiologia e Fitopatologia do Instituto Federal Catarinense - IFC/ Campus Rio do Sul e o experimento foi conduzido em delineamento inteiramente casualizado com cinco placas de Petri em cada tratamento. Foi utilizado isolado de $B$. squamosa obtido da coleta de conídios sobre o tecido foliar lesionado de mudas de cebola e multiplicado por sete dias a $20^{\circ} \mathrm{C}$ e no escuro em placas de Petri contendo meio de cultura BDA (Batata-Dextrose-Ágar). Após esse período, os conídios foram removidos através de lavagem com água esterilizada e pulverizouse com auxílio de um borrifador manual, $2 \mathrm{ml}$ de suspensão de $10^{5}$ conídios/mL em placas de Petri de vidro (90x15 mm) contendo $20 \mathrm{ml}$ de água destilada e 2 gramas de fragmentos em torno de $1,5 \mathrm{~cm}$ de comprimento de palha seca de folha de cebola previamente esterilizados em autoclave a $121^{\circ} \mathrm{C}$ por 25 minutos para simular a esporulação na folha após o desenvolvimento micelial sobre o tecido morto. Após a inoculação, as placas foram colocadas para incubação em câmaras de germinação do tipo B.O.D (Demanda biológica de oxigênio) nas temperaturas de $5,10,15,20,25$, e $30^{\circ} \mathrm{C}\left( \pm 1^{\circ} \mathrm{C}\right)$ no escuro por um período de quantificação da esporulação aos 14 dias após a inoculação no tecido foliar. A partir da obtenção da temperatura ótima para a esporulação, repetiu-se o ensaio seguindo a mesma metodologia acima, incubando-se com temperatura de $18^{\circ} \mathrm{C}$ (temperatura ideal conforme equação da figura 1A) nos fotoperíodos de 0, 6, 12, 18 e 24 horas, a fim de avaliar o fotoperíodo favorável a esporulação dos conídios. A contagem dos conídios foi feita através da retirada dos fragmentos da placa de Petri com $20 \mathrm{ml}$ de água de torneira e colocados em recipiente de vidro de $300 \mathrm{ml}$ com tampa rosqueável. Após sucessivas agitações manuais, a fim de desalojar os conídios presentes junto aos conidióforos e dos fragmentos da folha seca de cebola, estes foram coados em peneira plástica e o decoto contendo os conídios foram depositados em um Becker de $150 \mathrm{ml}$. Uma alíquota da suspensão de conídios foi coletada com uma pipeta de Pasteur e depositada em câmara de Neubauer para quantificação do número de conídios produzidos por placa em cada temperatura e fotoperíodo através da visualização de microscópio óptico com a objetiva de 10 vezes. Considerou-se a média dos conídios encontrados nos dois campos visuais da câmara de Neubauer. Constatou-se que a temperatura influenciou na esporulação dos conídios, apresentado melhor desenvolvimento entre as temperaturas de 15 e $20^{\circ} \mathrm{C}$ (Figura 1A), onde foram formados uma média de 392 e 97 conídios por placa respectivamente. Utilizando a equação gerada pela curva $\left(y=-1,358 x^{2}+47,9 x-228,8 ; R^{2}=0,383\right)$ (Figura 1A) obteve-
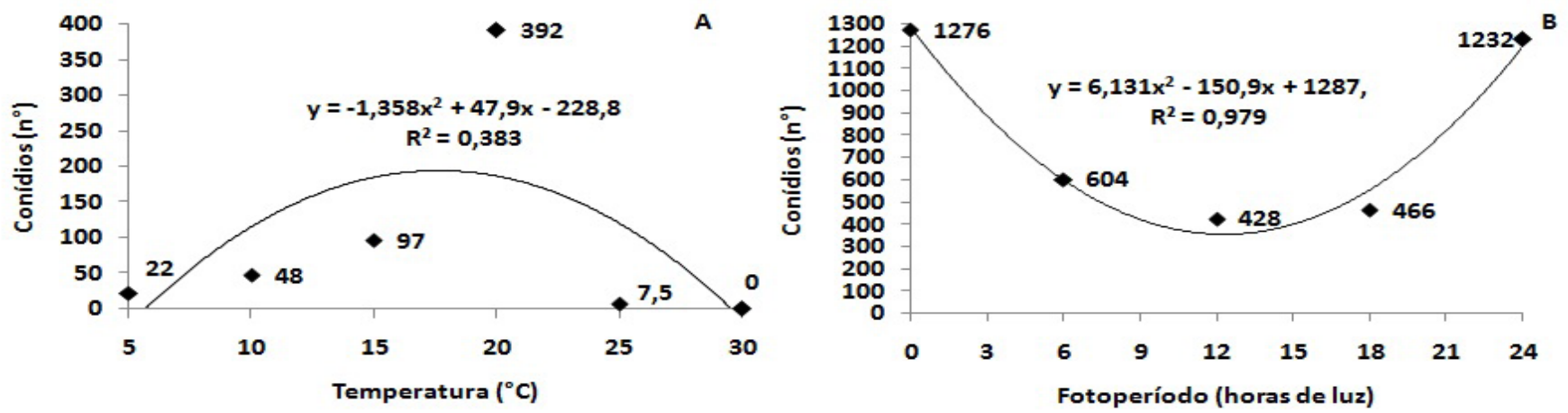

Figura 1. Curva do número de conídios de Botrytis squamosa produzidos in vitro em diferentes temperaturas (A) e fotoperíodos (B). IFC/Campus Rio do Sul, 2017. 
se a temperatura ótima de $18^{\circ} \mathrm{C}$ para a esporulação de conídios de $B$. squamosa. A temperatura de esporulação no presente trabalho esta na faixa dos 8 a $22{ }^{\circ} \mathrm{C}$ encontrado por Sutton et al. (1) nas condições de campo, mas o autor não detalhou a temperatura ótima para ocorrência da esporulação. Em relação a esporulação em diferentes fotoperíodos, observou-se a formação de uma linha polinomial (Figura 1B), que através da equação $y=6,131 x^{2}-150,9 x-1287\left(R^{2}=0,979\right)$, verificou-se que o fotoperíodo mais favorável ao desenvolvimento foi no escuro com 1279 conídios encontrados por placa quando comparado com 12 horas de luz que obteve apenas 426 conídios. Sutton et al. (1) também constatou que a esporulação acontece em períodos noturnos. O acentuado aumento na produção de conídios de 12 para 24 horas de luz (Figura 1B) provavelmente se deve ao estímulo reprodutivo para sobrevivência do patógeno. Desse modo, é possível que $B$. squamosa tenha sua esporulação favorecida por menores períodos de luz, assim em dias nublados e com pouca luminosidade como o que acontece durante o outono/inverno na região do Alto Vale do Itajaí durante o ciclo da cebola favorecem a esporulação dos conídios e a ocorrência da doença. Conclui-se que a esporulação dos conídios ocorreu em temperaturas de 15 a $20^{\circ} \mathrm{C}$, sendo a temperatura ótima de $18^{\circ} \mathrm{C}$, e no escuro. As informações obtidas em relação à temperatura e o fotoperíodo na esporulação de conídios de B. squamosa através da simulação de esporulação no tecido vegetal morto permitem um maior conhecimento da biologia do agente causal da queima das pontas da cebola, auxiliando no entendimento da epidemiologia e suporte para manejo da doença no campo. Os resultados obtidos servirão de suporte na elaboração de um sistema de previsão da doença.

\section{REFERÊNCIAS}

1. Sutton, J.C.; James, T.D.W.; Rowell, P.M. Relation of weather and host factors to an epidemic of botrytis leaf blight in onions. Canadian Journal of Plant Pathology, Ottawa, v.5, p.256-265, 1983.

2. Töfoli, J.G.; Ferrari, J.T.; Domingues, R.J.; Nogueira, E.M.C. Botrytis sp. em espécies hortícolas: hospedeiros, sintomas e manejo. Biológico, São Paulo, v.73, n.1, p.11-20, 2011.

3. Wordell Filho, J. A.; Boff, P. Queima acizentada - Botrytis squamosa Walker. In: Wordell Filho, J.A.; Rowe, E.; Gonçalves, P.A.S.; Debarba, J.F.; Boff, P.; Thomazelli, L.F. Manejo Fitossanitário na cultura da cebola. Florianópolis: EPAGRI, p.19-30, 2006 